Trabalho escravo: hoje 



\title{
Trabalho escravo no Brasil
}

\author{
DEPOIMENTO DE WALTER BARELLI e RUTH VILELA
}

E

STUDOS AVANÇADOS promoveu especialmente para esta edição o encontro de duas personalidades importantes para o debate que se trava atualmente sobre o tema trabalho escravo no Brasil contemporâneo: o economista WALTER BARELLI, ex-ministro do Trabalho e atual secretário do Emprego e Relações do Trabalho do Estado de São Paulo e professor do Instituto de Economia da Unicamp, e a procuradora doutora RUTH BEATRIZ VASCONCELOS VILELA, que chefiou o serviço de Fiscalização do Ministério do Trabalho e comandou o Grupo Executivo de Repressão ao Trabalho Forçado (GERTRAF). Eles estiveram juntos por mais de três horas na sede do Instituto de Estudos Avançados da USP, no dia 17 de março, relatando ao editor-executivo de ESTUDOS AVANÇADOS, jornalista Marco Antonio Coelho, suas experiências pessoais e profissionais. A seguir o leitor poderá conferir o resumo das declarações desses especialistas.

ESTUDOS AVANÇADOS - As primeiras questões seriam as seguintes: como se apresenta, hoje, no Brasil, o trabalho escravo? Quais são as suas características, onde ele é mais freqüente $\mathrm{E}$, também, queria adiantar a questão do endividamento forçado, e que tem levado exatamente ao estabelecimento de uma relação de trabalho escravo. Em seguida, pediria uma estimativa sobre a existência dessa relação trabalhista aqui no Brasil, no momento.

Walter Barelli-Acho importante dizer que a Ruth era da minha equipe, no Ministério do Trabalho. Acredito que facilitaria o entendimento se eu fizer um histórico. Esse tema foi levantado, no governo de Itamar Franco, com bastante força. Posteriormente tivemos diversas ações, com a criação de um grupo especial, no governo Fernando Henrique, de erradicação do trabalho forçado. O grande problema com que nos defrontávamos era uma denúncia internacional, feita pela Comissão Pastoral da Terra (CPT), em Genebra, sobre o trabalho escravo no Brasil. Então, precisava-se caminhar para a erradicação desse tipo de trabalho, demonstrar que não era da índole do governo Itamar, e nem do governo Fernando Henrique, apoiar essas formas não-civilizadas de exploração do trabalho. No meu tempo no Ministério, como agimos? Criamos inicialmente um Conselho Nacional do Trabalho, que era uma comissão tripartite composta pelos representantes de todos os setores que deveriam se responsabilizar, como sociedade, pela 
política trabalhista no Brasil: desde as centrais sindicais, todas as confederações patronais, representantes do governo, principalmente das áreas que se relacionavam com trabalhadores. Dentro desse grupo foi instituído um subgrupo que tratava especificamente do trabalho escravo. $\mathrm{O}$ projeto não estava totalmente realizado, mas uma vez identificado o trabalho escravo, ou, tendo alguma pista, se não me engano, eu verbalizei na época a proposta de colocar todo o Conselho Nacional do Trabalho dentro de um avião e descer no local onde havia o trabalho escravo.

Vejo a mudança no mundo do trabalho como um processo civilizatório. Se a sociedade, por meio dos empresários e dos trabalhadores, não assumir a questão, ela se torna uma questão a ser tratada no submundo, quase como uma questão policial. Tinha de ser uma questão de cidadania, a idéia era essa. Quase conseguimos a primeira dessas operações em Barreiras, na Bahia. Não foi possível coordenar tudo em termos de se atingir essa meta, mas o sonho, o desenho da ação iria ser esse. O Ministério do Trabalho tem equipes de fiscais habilitados para tratar a questão. Na época, fizemos uma operação que se concentrava entre Belém e Marabá. Houve uma denúncia de trabalho escravo e fomos investigar, com a polícia federal. Duas equipes, uma saindo de Belém, outra de Marabá, para tentar localizar. Mas à medida em que qualquer ação é noticiada ou haja qualquer indício de investigação, as pessoas desaparecem com os trabalhadores e desaparecem os fazendeiros. É uma situação peculiar e a doutora Ruth vai ter muito o que contar. Eu sou mais uma pessoa que atuou primeiramente em militância anterior no Dieese, e depois nessa participação no governo.

Ruth Vilela - O trabalho escravo não se apresenta, ele se esconde, somente existe à medida em que não há foco sobre ele. Todas as pessoas têm conhecimento sobre o trabalho forçado, mas ele não pode aparecer no dia a dia. Então, ele tem de se esconder sob outras formas.

Walter Barelli - A questão do endividamento é a maneira pela qual o trabalho escravo é mais um trabalho forçado, que não permite aos trabalhadores saírem de onde estão por se considerarem devedores das pessoas que os contrataram. Existia muito isso nas lavouras de cana-de-açúcar, porque eram feitas muito pelos volantes - os chamados bóias-frias - que vinham de outros locais do território nacional, contraíam dívidas que normalmente eram feitas com os fazendeiros e posteriormente passaram a ser feitas com o gato. Agora, à medida em que as áreas canavieiras vão tendo maior integração, as chamadas forças produtivas vão se organizando de forma diferente, o endividamento vai desaparecendo. As formas de endividamento ainda existem, mas a possibilidade de denúncia passa a ser grande. Na medida que o 
movimento sindical rural cresceu, se organizou, a maioria dos municípios passou a ter sindicados e havia a possibilidade de denúncias. O dirigente sindical, protegido pela estabilidade do dirigente - se não corrompido tinha interesse em denunciar, por ser essa uma das maneiras de mostrar que estava representando os trabalhadores. À medida em que cresce a organização das forças produtivas num estado, como acontece em São Paulo, fica difícil aparecer o trabalho escravo, e ele vai se refugiando em determinados locais, normalmente em regiões denominadas fronteiras agrícolas, onde a sociedade é menos organizada: são nessas regiões que se têm notícias de trabalho forçado.

Durante minha gestão no Ministério, as denúncias provinham do interior do Piauí, do Maranhão, do Pará, do Amazonas e do Mato Grosso. Havia também situações de desrespeito até no estado de São Paulo, principalmente relativas ao pessoal que trabalhava na extração de resinas - de árvores - no sudoeste paulista, na região do Pontal do Paranapanema, onde a organização era menor e as cidades praticamente inexistiam. Os trabalhadores trabalhavam embrenhados no mato e o trabalho escravo acontecia. Algumas características podem ser citadas. Além de não haver organização dos trabalhadores, ou seja, sindicatos, há muita ignorância. Trata-se de pessoas que não são da região, normalmente contratadas em outros locais. A essas pessoas é prometida uma recompensa em termos de rendimento, que as atrai e que sempre funciona como estímulo para continuar na região. A organização do trabalho, que é rudimentar, precisa de feitor, do carrasco, para manter a disciplina. O trabalho tem de ser feito e a pessoa não pode fugir dele. A disciplina é obtida por débitos que o trabalhador mantém com o barracão, pela passagem adquirida para seu deslocamento até o local de trabalho, por algum adiantamento que lhe foi fornecido anteriormente. A partir daí, é obrigado a exercer suas funções de acordo com o que, aparentemente, era um contrato verbal estabelecendo tais condições - derrubar tantos hectares de mata, ou exercer algum tipo de atividade desse naipe.

É muito difícil estimar o número de trabalhadores que exercem suas funções de forma escravista, porque uma vez denunciado o trabalho forçado ele deixa de existir, porque hoje a sociedade brasileira já tem a possibilidade de ação. O Ministério do Trabalho, mediante fiscalização, tem condições de, havendo vontade política, atuar sobre o problema. E isso vem ocorrendo pelo menos desde outubro de 1992. Qualquer mancha causada pelo trabalho escravo é uma mancha contra o Brasil. Por ocasião do impeachment de Collor, o governo Itamar demonstrou vontade política expressa, manifesta, de que essa mancha deveria ser removida da nossa história. 

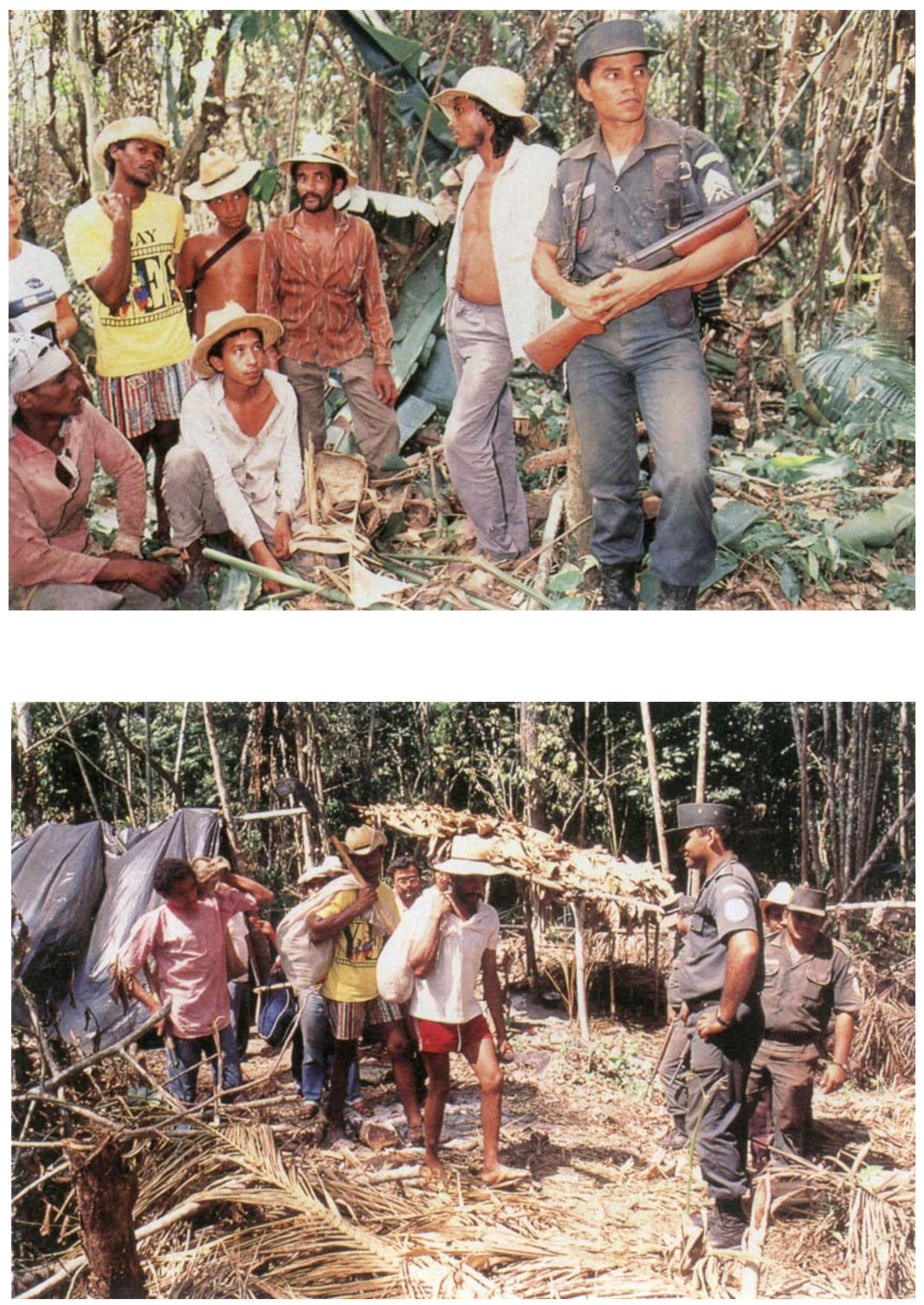

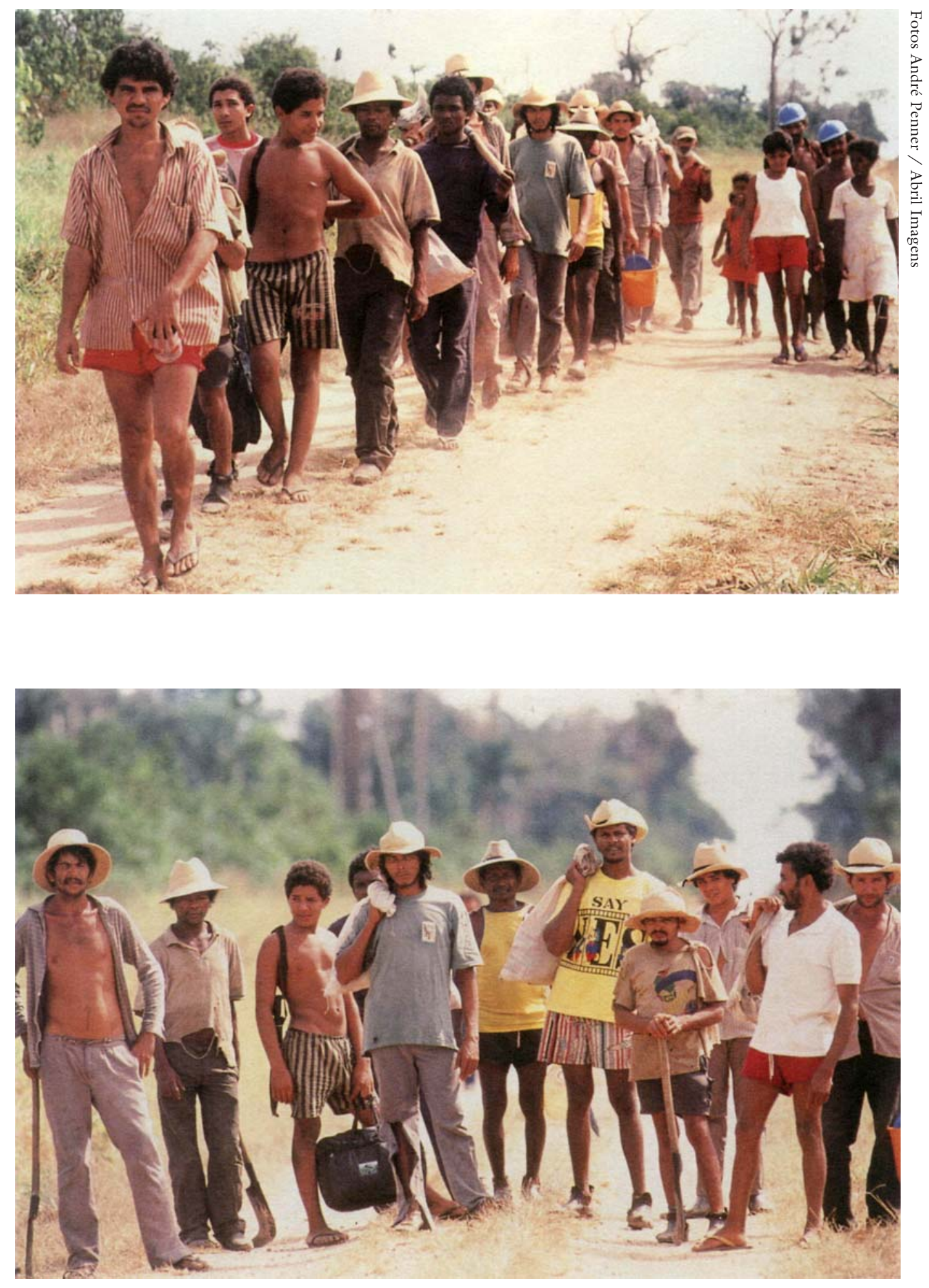

Flagrantes do momento em que lavradores escravizados na Fazenda Santana, em Ourilândia do Norte, $P A$, são libertados pela polícia no interior da mata 
Das estimativas que existiam, em 1993 a minha equipe elaborou um dossiê, entregue ao professor Roberto Santos, um célebre jurista brasileiro que também estudou aqui, na USP, e é, acredito, paraense, e foi presidente do Tribunal Regional do Trabalho, na $8{ }^{a}$ Região de Belém. A defesa que fez do governo brasileiro na OIT foi exemplar. Em termos jurídicos, ele é uma autoridade, com várias obras publicadas, além de ser economista.

Voltando às estimativas, elas normalmente são mencionadas pelos críticos do governo, entre eles a CPT. Esta fornece números do trabalho escravo, números sempre computando o trabalho escravo que houve, pois uma vez denunciado, ele deixa de existir. Quando se trata desse tipo de estimativa, aborda-se uma realidade da época em que os números foram levantados; uma vez constatado esse tipo de trabalho ele desaparece, desaparecendo com ele uma atividade que envergonha as pessoas. Assim, a estimativa é impossível de ser feita.

\section{As ações do governo}

$R u t h$ Vilela - Seria interessante que eu fizesse também uma introdução para falar rapidamente do meu contato e da minha experiência com o tema. Em 93 estive na equipe do ministro Barelli. Era secretária adjunta da Secretaria de Fiscalização. Em 94 voltei ao meu órgão de origem em Belo Horizonte, a Delegacia Regional do Trabalho. Em 95, a convite do ministro Paulo Paiva, retornei à Secretaria de Fiscalização, tendo permanecido à frente dela até início de 99.

Nesse período, exatamente no ano de 93, por pressão da sociedade civil organizada, notadamente da Comissão Pastoral da Terra, o assunto tornou-se bastante relevante não só em razão de denúncias feitas à Organização Internacional do Trabalho, mas da pressão e do questionamento de diversas instituições da sociedade na época. Não me envergonho de dizer que, apesar de ingressar na carreira da fiscalização em 75 , só vim a tomar conhecimento, a ter contato com a realidade do trabalho escravo, a partir de 93, quando em exercício desse cargo no Ministério do Trabalho.

Portanto, mesmo sendo uma técnica da área do trabalho, as notícias sobre trabalho escravo significavam para mim alguma coisa remota que ocorria especificamente no estado do Pará. Acredito, inclusive, não ser vergonha para as pessoas em geral admitir que não têm muito conhecimento a respeito dessa realidade, porque não a conhecem em detalhes. Até nós, que somos do mundo do trabalho, apenas em razão do ofício, às vezes tomamos conhecimento direto de tais ocorrências. 
Em 93, na época em que trabalhei com o ministro Barelli, queria lembrar que foi editada a primeira Instrução Normativa, dando orientações e determinando procedimentos à fiscalização no trato com a questão do trabalho escravo ou forçado. Essa Instrução, portanto, foi o primeiro ato oficial que colocou a fiscalização como uma das co-responsáveis pelo projeto de erradicação do trabalho escravo. A partir de 95, no governo Fernando Henrique, logo que assumi a Secretaria de Fiscalização, no primeiro contato que tive com o ministro Paulo Paiva, quando mencionou as minhas incumbências, ele destacou que as questões relacionadas com o tema teriam a maior ênfase. Quando me fez essa recomendação a fez em nome do presidente da República, afirmando que não poderíamos conviver com esse tipo de exploração do trabalho, ou admiti-lo, porque no fundo são atividades criminosas e ilícitas.

Como já mencionado, tínhamos como instrumento para a fiscalização aquela Instrução Normativa. Entretanto, à época em que ela foi elaborada, não tínhamos precedentes, não tínhamos experiência anterior, por isso ela evidentemente era tímida com relação à complexidade e à magnitude do problema. Pela experiência adquirida em 93, resolvemos repensar e encontrar uma forma que nos propiciasse maior eficácia nas ações, maior agilidade no trato da questão e, principalmente, a adoção de medidas, instrumentos e procedimentos que pudessem superar questões políticas locais ou eventuais pressões políticas exercidas sobre as autoridades regionais e da fiscalização local.

A necessidade de garantir eficácia fez com que procurássemos reunir uma equipe especial que trabalhasse sob o comando direto da Secretaria de Fiscalização em Brasília, de modo a garantir uniformidade de procedimentos, eficiência, agilidade, mas, acima de tudo, garantir o absoluto sigilo a respeito da operação que seria desenvolvida. Mediante uma Portaria ministerial, foi criado esse grupo especial, denominado Grupo Móvel de Fiscalização.

Ao mesmo tempo, por outra medida mais técnica e mais localizada, foi instituído pelo presidente da República, no próprio Ministério do Trabalho, um grupo interinstitucional e interministerial, o Grupo Executivo de Repressão ao Trabalho Forçado (GERTRAF), com o propósito de transformar o programa de erradicação do trabalho escravo muito mais em um plano de governo do que propriamente uma ação isolada do Ministério do Trabalho. O Gertraf é coordenado pelo Ministério do Trabalho, mas conta com representantes dos ministérios do Meio Ambiente, da Política Fundiária, da Justiça, da Agricultura, da Previdência e até mesmo do exMinistério da Indústria e Comércio, hoje do Desenvolvimento. Esse grupo 
tem como proposta, além da apuração propriamente de denúncias recebidas, pensar políticas públicas adequadas para atingir o objetivo final proposto, a erradicação dessa forma ilícita de exploração do trabalho.

Com o decorrer do tempo, pode-se dizer que o Grupo Móvel de Fiscalização teve desempenho acima da média e conseguiu resultados bastante surpreendentes. Durante quatro anos - de 95 a 98 - conseguimos sofisticar um pouco as ações do grupo. Conseguimos treinar melhor seus componentes e, recebendo denúncias, colocar de imediato a equipe em campo, no prazo recorde de 72 horas no máximo. Enfim, conseguimos aprimorar as ações e gerar grandes resultados.

Vou ser sincera com relação ao resultado do grupo interministerial. Ele não gerou os resultados esperados, seja porque os ministérios não se preocuparam em indicar representantes que tivessem algum poder de decisão, seja porque o grupo era composto por pessoas da área técnica, as quais, quando voltavam para seus respectivos ministérios, geralmente tinham certa dificuldade de se fazer ouvir pelos próprios dirigentes. Assim, considero a experiência GERTRAF, infelizmente, não tão bem sucedida quanto a do Grupo Móvel de Fiscalização. Entretanto, não é uma experiência que se possa desprezar. A minha proposta seria reestudá-la e aprimorá-la, por entender que a elaboração e a execução de políticas públicas para a erradicação do trabalho escravo não depende somente do Ministério do Trabalho. Depende de uma série de outras medidas concernentes aos ministérios da Agricultura, do Desenvolvimento e do próprio Ministério da Justiça, que permanentemente deve ser partícipe dessas questões, pois suas equipes são acompanhadas pela polícia federal. Enfim, essa é uma experiência que deve ser resgatada e aprimorada.

Durante o período em que estive gerenciando o programa de erradicação do trabalho escravo aprendi muito. Acima de tudo, aprendi que toda a discussão em cima do rótulo propriamente - trabalho escravo, trabalho degradante, trabalho forçado - é importante para efeito das questões da Justiça, mas é pouco relevante do ponto de vista da execução das políticas públicas. Isso porque, fugindo da utilização de termos mais técnicos ou jurídicos, a situação mais grave é exatamente aquela que a equipe sempre encontrou na região mencionada pelo professor Barelli - a Amazônia Legal principalmente a região denominada de Bico do Papagaio.

Tal situação pode ser definida como negativa do Direito. Se traçarmos um paralelo entre essa situação e, por exemplo, um contrato de trabalho normal, poderíamos dizer que no trabalho escravo o que está presente na parte nuclear dessa relação é a coerção. $\mathrm{O}$ empregador se apropria do 
excedente mediante coerção. Daí, podem surgir duas situações, se se quiser voltar ao passado: tanto se constata uma situação de escravidão, quanto se pode constatar uma situação de servidão. Em ambos os casos, o mecanismo é muito simples. O empregador utiliza a coerção para se apropriar do excedente e, para tanto, utiliza vários instrumentos.

É exatamente essa parte que se contrapõe a um contrato de trabalho normal, por mais precárias que sejam suas condições. E por que? Porque estão inerentes ao contrato de trabalho exatamente liberdade e vontade. Mesmo quando se examina uma relação de trabalho absolutamente precária, liberdade e vontade vão estar presentes: no início da relação, quando se resolve aderir àquele contrato, escolher aquele emprego, por menores que sejam as opções no final do contrato de trabalho, o binômio liberdade/ vontade estará presente porque o trabalhador tem, acima de tudo, o direito de dar fim àquela relação.

Na situação chamada de escravidão, a liberdade e a vontade são inexistentes. O que existe é a coerção. Outro aspecto da escravidão: o trabalhador não se desliga definitivamente dos meios de produção porque a coerção se estende até à sua vida pessoal, o que no contrato de trabalho definitivamente não deve existir, por pior que seja a relação. $O$ trabalhador tem vida própria e o poder do empregador não se estende até a sua vida pessoal. $\mathrm{O}$ trabalhador deve continuar com a possibilidade de ter a sua vida pessoal, a sua liberdade pessoal, o que definitivamente não acontece nesses casos chamados de escravidão branca ou contemporânea.

A partir do momento em que o trabalhador passa por todas aquelas etapas, a partir do momento do recrutamento, do aliciamento, até o momento em que ele se encontra na propriedade e inicia as suas atividades, num crescendo vai sendo envolvido naquela situação. Gradativamente, desde o momento do recrutamento, durante a viagem, a permanência por alguns dias nas pensões, até o início das atividades, ele, passo a passo, vai renunciando exatamente a essa liberdade, a essa vontade.

\section{Por que e como os trabalhadores são escravizados?}

Ao contrário do que as pessoas possam imaginar, essa relação de escravidão contemporânea, essa situação de trabalho escravo, muito embora ocorra nas regiões mencionadas e em situações nas quais a sociedade não está organizada, em que não existe sindicalismo organizado, em regiões mais pobres, ao contrário do que todos imaginam, tal relação depende de um sistema altamente sofisticado. Por que esse sistema é sofisticado? Porque ele é pensado de forma extremamente inteligente. Em primeiro lugar, 
os trabalhadores são recrutados em uma região que não é aquela na qual vão prestar o trabalho. Esse fato tem todo um significado. Por que tal aspecto interessa? Porque são cortados os vínculos que o trabalhador tem com seu local de origem, com sua família, com seus amigos. Esse é o primeiro pré-requisito para que a coerção seja exercida de uma forma mais eficiente. Em segundo lugar, o que constitui o primeiro de uma série de crimes que vão sendo cometidos ao longo desse caminho: a contratação mediante promessas enganosas. São prometidos bons salários, boas condições, acima de tudo a possibilidade de aquele trabalhador trabalhar durante alguns meses para depois retornar para casa e para a família, tendo economizado uma certa quantia em dinheiro, que garantiria a sobrevivência dele e da família por algum tempo.

Essas falsas promessas dizem muito a respeito ao sonho de cada trabalhador individualmente, que é fazer um sacrifício durante algum tempo para poder voltar para casa, inclusive recebendo o apoio e o reconhecimento de seus familiares, com recursos suficientes para conseguir sobreviver durante algum tempo e poder realizar determinados sonhos: o sonho que se refere a um local para morar, um sonho que se refere à educação dos filhos, que se refere a um sonho mínimo da mulher de ter um fogão decente... E o trabalhador, com relação a essas falsas promessas, é absolutamente vulnerável. Se ele parasse de sonhar, poderia optar pela marginalidade absoluta, que é também eventualmente uma forma de libertação. Os trabalhadores rurais têm um perfil diferente do dos trabalhadores urbanos, que nunca deixaram suas atividades. Conseguem reter uma pureza e uma ingenuidade que ainda permitem o sonho. E, por ironia do destino, é justamente essa pureza, essa capacidade de sonhar, que serve como um dos mecanismos de coerção, principalmente no momento em que são recrutados. Porque é o sonho que faz com que o trabalhador aceite essa proposta de trabalho, mesmo tendo de temporariamente abandonar a família e ir para lugar desconhecido.

No momento do recrutamento, quando os trabalhadores aceitam a proposta do gato - a figura que vai em busca desses trabalhadores e os recruta - o segundo crime acontece, sem que eles o percebam. Todo e qualquer documento dos trabalhadores fica em poder do gato, e esse é o segundo passo em direção à perda de mais um pedacinho daquilo que compõe a dignidade humana. $\mathrm{O}$ trabalhador está perdendo os seus liames com a família, com os amigos etc. Ao entregar seus documentos para o gato, dá mais um passo na direção de não ser ninguém, porque os documentos não serão devolvidos aos trabalhadores a não ser no final desse contrato, entre aspas. 

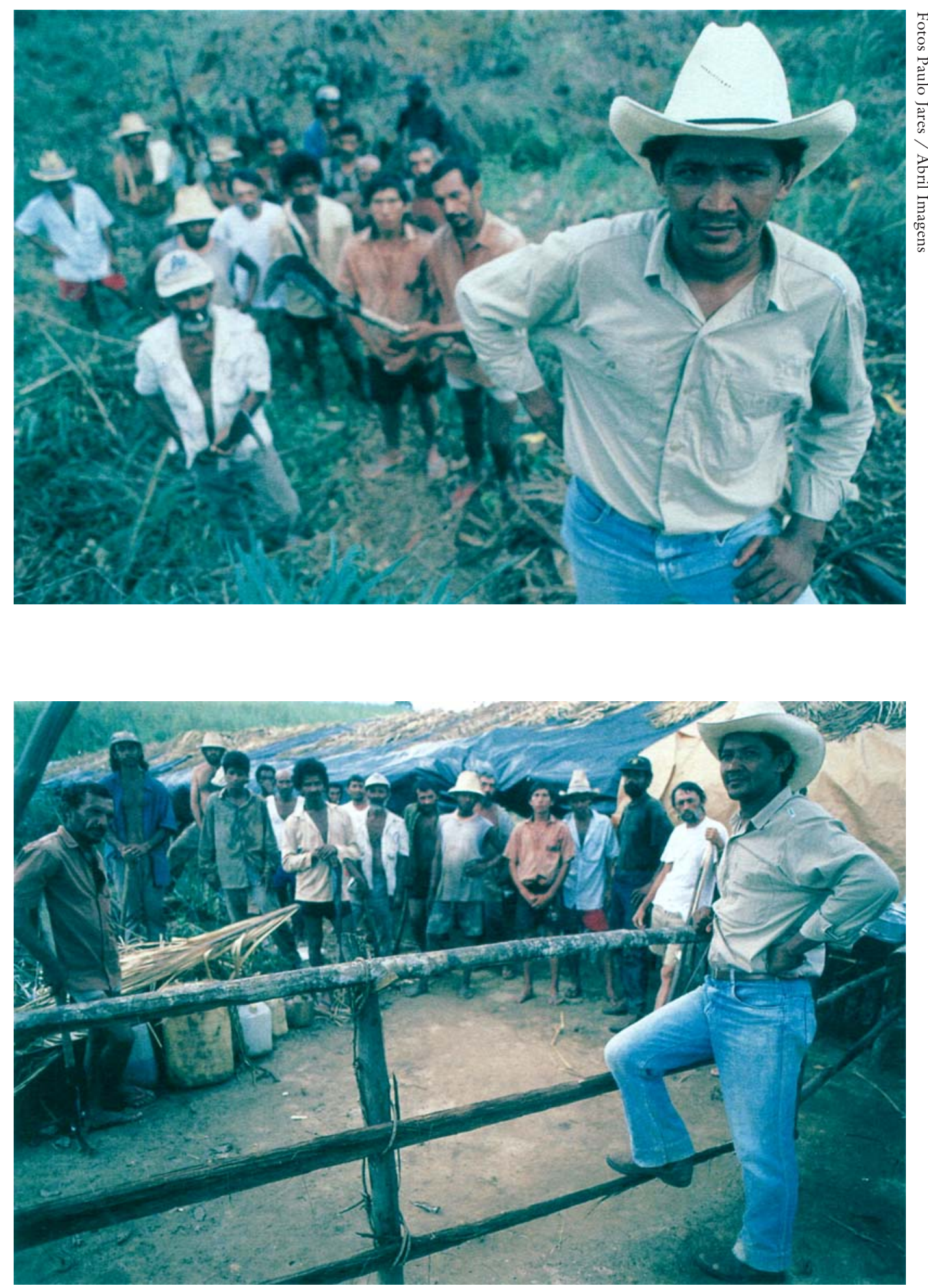

À frente o gato Valdivino Luiz Antunes, dona da Cardejal, empresa que contrata mãode-obra temporária para fazendas, em Paraupebas, $P A$ 
Durante a viagem começa o processo de endividamento, sem que os trabalhadores saibam o que está ocorrendo. É comum esse endividamento começar ainda na praça, no momento do recrutamento. Alguns gatos oferecem algum dinheirinho para o trabalhador deixar para a família ao partir. Assim, o endividamento ou começa nesse momento, quando há qualquer espécie de adiantamento em dinheiro, ou com alimentação e todos os gastos inerentes à viagem, e se prolonga posteriormente, naqueles casos em que os trabalhadores, ao chegarem, são deixado em pensões. Os donos das pensões, por sua vez, fazem parte de toda essa rede que culmina no trabalho escravo. Pode-se, então, ter duas situações diferentes: existem os gatos que recrutam contingentes de trabalhadores para um contratante determinado, mas também há alguns que conduzem os trabalhadores para determinadas localidades, deixam os trabalhadores em pensões, e o endividamento continua, porque eles consomem na pensão - comem, bebem etc. Posteriormente, um outro gato comparece na pensão e compra o trabalhador, ou seja, paga a dívida anterior contraída com o outro gato, e o contrata, conduzindo-o para determinada propriedade rural. É só então que o trabalhador vai começar as atividades de seu trabalho.

Quando ele é conduzido para essa propriedade, corta-se o último elo de ligação com a civilização, ou com qualquer possibilidade de manter um novo contato com a família, ou com quem quer que seja. O trabalhador não sabe para onde foi conduzido e, nesse momento, outro fenômeno acontece: ele acaba se submetendo totalmente, porque não sabe onde está, tampouco como sair dali. Duas situações podem acontecer: o cerceamento de liberdade pode ocorrer pela simples localização da propriedade, se ela for de difícil acesso, ou por vigilância armada. Essas duas formas ocorrem dependendo das circunstâncias. Em alguns casos, não é notada a presença desses dois aspectos: nem a área é de difícil acesso, nem há propriamente vigilância armada, mas a coerção se dá mediante ameaça, sem a necessidade de armamento ostensivo. Isso pode acontecer dependendo do nível de sujeição dos trabalhadores.

O limite da jornada de trabalho desses trabalhadores é a própria natureza, ou seja, enquanto for possível trabalhar, se trabalha... Os alojamentos são típicos do meio rural, improvisados com estacas, geralmente fechados com plástico na cor preta. Não há qualquer tipo de garantia de privacidade, geralmente nem nos alojamentos, nem nos banheiros, também improvisados. A comida é de péssima qualidade, sem seguir as regras mínimas de higiene. É comum que as fontes de água para beber estejam contaminadas porque os trabalhadores vão às fontes de onde bebem e também fazem ali as suas necessidades. Isso faz com que, em geral, quando uma turma de 
trabalhadores nessas condições é descoberta, todos estejam doentes, muitos já tenham sofrido acidentes de trabalho graves, sem que tenham recebido qualquer tipo de atenção ou socorro.

Há uma imagem interessante que pode fazer as pessoas entenderem bem o que é encontrado: quando se entra em uma propriedade rural e, por exemplo, se vai em direção aos estábulos, o que se nota é que são construídos em alvenaria, geralmente caiados de branco. Os animais são bem cuidados, há sempre alimentação, água e um veterinário para aplicar as vacinas adequadas etc. O tratamento dispensado aos animais, ao gado, de maneira geral é mil vezes melhor do que o tratamento dispensado aos trabalhadores.

O mais grave de todo esse procedimento refere-se aos contatos mantidos com proprietários rurais nas diversas ações de que participei pessoalmente. Normalmente eles encaram a situação como absolutamente normal. Quando se fala para um empregador sobre a necessidade, por exemplo, de fornecer equipamentos de proteção individual do trabalhador, esses bem básicos, adequados à atividade, como um sapato fechado, uma botina mais apropriada para proteger contra a foice, ou um chapéu de palha para proteger contra o sol, eles acham que essa determinação é um total absurdo. Consideram um absurdo a lei determinar que essa seja uma obrigação do empregador.

É comum observar que os próprios instrumentos de trabalho utilizado pelos trabalhadores nessa situação não são do empregador. Os trabalhadores em geral são obrigados a adquirir os seus instrumentos de trabalho também no barracão, e pagar por eles. Outra imagem que os empregadores têm é de ser simplesmente um absurdo o elenco de direitos trabalhistas previstos inclusive na Constituição. E fazem comentários muitas vezes expressos a respeito dos trabalhadores serem ladrões, preguiçosos, safados e que normalmente roubam. Essa é a visão do empregador. Na realidade, acreditam que se não utilizarem todo esse mecanismo de coerção não conseguem fazer com que o trabalhador produza. É uma concepção arraigada e torna-se muito difícil estabelecer um diálogo, tentando fazer com que eles ouçam as razões legais. Razões que além de legais são também humanitárias em defesa daquele mínimo de dignidade que qualquer ser humano merece. É uma relação difícil de ser mudada, no meu modo de entender. Assim, a questão de mudança de mentalidade é uma das condições sine qua non para se chegar ao objetivo final, que é efetivamente erradicar essa prática.

Esse tipo de trabalho constitui um crime contra o trabalhador, é ilícito e, portanto, se dá na sombra, escondido. Ele vem à luz quando se recebe a denúncia. Temos, por exemplo, dados sobre trabalhadores libertados nas 
ações empreendidas pelo Ministério de Trabalho, nas quais a equipe obteve sucesso. Mas construir dados estatísticos é mais complicado porque um dos aspectos tristes, que temos de admitir, refere-se a que vários trabalhadores libertados de determinada situação, por falta de opção em sua própria cidade, no seu local de origem, mesmo sabendo de todo o horror que deverá ser enfrentado, é normal que voltem e trilhem o mesmo caminho e passem pela mesma via crucis. Pode-se até estabelecer estimativas, mas dados oficiais estatísticos confiáveis é algo a que dificilmente se conseguiria chegar. Para que essa situação não seja superestimada, nem subestimada, diria que são muitos os trabalhadores e que a situação é tão grave e atinge a tantos, não só nessa região mencionada, mas em outras, às quais talvez não se tenha tido acesso.

Mas, da experiência que adquirimos concluímos que essa situação é a negativa do Direito, ela é também a negativa do Estado de Direito, ela é negativa da democracia e é a negativa de qualquer proposta de desenvolvimento que se possa ter para este país. São muitos os trabalhadores nessas condições e ainda que não se possa taxativamente numerá-los, diria que são em número suficiente para ocupar nossos corações e nossas mentes durante o tempo necessário, até que essa prática seja finalmente erradicada.

\section{Indicações para uma política governamental}

ESTUDOS AVANÇADOS - Vamos então passar para aquilo que é fundamental, ou seja, como continuar esse trabalho para erradicar essa forma brutal de exploração do homem. Coloco numa mesma pergunta as seguintes questões: de um lado, que pressões existem pela manutenção desse sistema de trabalho em algumas regiões do Brasil e o que deve ser feito, do ponto de vista meramente dos órgãos executivos governamentais do Estado brasileiro, no sentido de levar avante essa luta pela erradicação do trabalho forçado com os meios legais que existem dentro do Código Penal, na legislação do trabalho ou mesmo na Constituição? Que passos devem ser dados do ponto de vista legal para aprimorar esse trabalho de erradicação? Postula-se a necessidade de criminalizar esse tipo de trabalho, porque, na revisão do Código Penal, alguns autores acreditam ser insuficiente o que consta dele, e também na própria legislação do trabalho. Gostaria de saber a opinião dos dois, levando-se em conta essa situação econômico-social que vocês descreveram muito bem.

Walter Barelli - No caso brasileiro, em alguns momentos, tenta-se mascarar a realidade. Na região de Ribeirão Branco, sudoeste paulista acima do Vale do Ribeira, os tomateiros eram apresentados como arrendatários 
das terras. Pareciam pessoas em melhor situação porque eram arrendatários, eram pessoas mais próximas do empregador. Entretanto, ocorria o contrário, a forma da maior exploração possível, porque não garantia nem um tipo de renda. Empregador e empregados eram sócios, praticamente, do prejuízo. A ação do Ministério Público e do Ministério do Trabalho fez com que essas pessoas tivessem contrato de trabalho, estabelecessem uma relação trabalhista. Mas, sentia-se a pressão exercida pelos empregadores, ao se manifestarem: "nós demos a eles as terras, eles têm um contrato conosco..." Estou apresentando esse exemplo como uma forma de sofisticação. Em termos de pressão, pessoalmente, nunca recebi pressão alguma como autoridade, por ser impossível haver defensores do trabalho forçado da maneira como é feito. O que é grave acontece nas fronteiras agrícolas. Nelas, não há lei, a lei é feita pelas pessoas. Mas, à medida em que chega um arremedo de civilização as coisas vão começando a mudar. O que o Estado tem de fazer? A maneira que eu vejo de o Estado resolver esses problemas é aumentar o grau de participação da sociedade mediante mecanismos de cidadania.

Estamos tratando dessas manchas que foram denunciadas, como um indivíduo que foi mantido prisioneiro numa determinada área florestal. Agora, o trabalho escravo existe também de outras maneiras. Por exemplo, a empregada doméstica, em vários locais, trabalha num regime forçado, ela apanha, sofre castigos físicos, corporais, não tem remuneração legal, o salário mínimo não existe em determinadas regiões. Essas formas todas de exploração do trabalho, à medida que o Brasil vai se conhecendo, vão ter de ser enfrentadas. Fala-se no trabalho de carvoaria, do desmatamento, é disso que se trata normalmente. São situações que tendem a ter seu fim: à medida que acabar o carvão, ele passará a ser substituído por outro tipo de componente. A ação que tem sido empreendida é de criar o salário escola para o filho do carvoeiro e outras providências... assim, as relações de trabalho vão se modificando.

Temos essas manchas de trabalho forçado dentro de qualquer cidade brasileira, e quanto menos cidadã é a cidade mais essas práticas existem. Quando se visita determinadas regiões do país as relações de trabalho são de servidão. Então, o que fazer do ponto de vista do Estado? A fiscalização precisa estar mais presente, mas é difícil. Se temos dificuldade de fiscalizar o trabalho nas regiões industriais imagine-se no campo e nas regiões de fronteira. A coisa fica mais complicada. No meu ponto de vista, a equipe de fiscalização deverá contar em suas ações com o envolvimento da sociedade. Á medida em que a sociedade começa a combater o trabalho escravo, ou trabalho forçado, muda a situação. 
Do ponto de vista legal, lógico, são indispensáveis as punições exemplares. A maior delas, principalmente no campo, é a expropriação da terra, é a reforma agrária. Fora do campo, a quem atente contra as leis que regem o trabalho, devem ser aplicadas penalidades também. São crimes que devem ser punidos de maneira exemplar. A privação da liberdade é pouca punição pela exploração que é feita. As pessoas devem sentir na carne ou no bolso o castigo pelo que cometeram.

Ruth Vilela - O trabalho, de certa forma pioneiro no trato da questão, feito pelo Grupo Móvel de Fiscalização nas ações empreendidas, mais de caráter repressivo, foi um passo de qualidade enquanto ação do Executivo, enquanto manifestação de vontade política do governo. Entendo que esse trabalho tem muito mérito porque ajudou a dar maior visibilidade ao problema. Porém, diante da gravidade da situação, é ainda um grão de areia, porque não conseguimos, apesar de todos os resultados positivos, garantir eficiência para interromper essa cadeia de atos constantes e sucessivos que propiciam o trabalho escravo. Mesmo assim, temos conseguido apurar as denúncias, resgatar os trabalhadores, garantir o pagamento daquilo que eles têm direito em razão do trabalho. Temos garantido o retorno dos trabalhadores ao local de origem, temos conseguido dar identidade a esses trabalhadores. Um dos procedimentos adotados é garantir registro na carteira de trabalho. Isso a equipe tem garantido, mesmo para aqueles trabalhadores que não portam documentos, e emite-se a carteira de trabalho. O trabalhador sai daquela situação com um documento, que é a sua carteira de trabalho, com anotações feitas pelo empregador, registrando o período em que esteve em atividade. Recebe as verbas rescisórias e a garantia de seu retorno ao local de origem em ônibus

Houve um salto de qualidade, mas a ação termina aí. Aquele grupo de trabalhadores retorna ao seu local de origem. Durante algum tempo, com aquelas verbas que ele recebeu, vai conseguindo sobreviver e quando o dinheiro termina, se no seu local de origem não tiver sido criada qualquer expectativa de trabalho, por mais precário que seja, de novo ele vai entrar nessa cadeia de eventos que conduz ao trabalho escravo. Assim, apesar de todo o mérito, não podemos afirmar que o trabalho escravo está sendo erradicado. Estamos dando visibilidade, de certa forma, a essas ações. Elas sacodem a comunidade onde são realizadas. Estabelecem algum tipo de diálogo e exercem forte pressão sobre os empresários rurais da região, sem dúvida alguma. Mas com relação aos trabalhadores propriamente, não conseguimos avançar de modo a lhes garantir que possam sair do inferno e não terem de voltar para lá novamente, ainda que no seu lugar de origem eles permanentemente tenham de viver em purgatório. 
Diante desse quadro, seria ingenuidade nossa entender que a alteração do Código Penal e a modificação das leis trabalhistas, seriam instrumentos suficientes para coibir esse tipo de prática e para nos levar à erradicação final dessa situação. Acho os instrumentos legais importantíssimos porque garantem a recomposição do dano em relação ao trabalhador. Garantir a punição seria muito interessante, principalmente se essa punição tivesse repercussões no patrimônio daquele empregador, como mencionado pelo Barelli. A questão da expropriação seria mais adequada do que uma proposta de desapropriação.

Enfim, muitos mecanismos podem e vão com certeza ser gradativamente alterados tanto na legislação trabalhista quanto na reforma do Código Penal. No meu modo de entender, entretanto, a letra fria da lei fica no papel. Se os agentes públicos não estiverem preparados e interessados para fazer cumprir aquilo que o legislador estabeleceu como norma de defesa dos interesses da sociedade, tais normas ficarão esquecidas, como de certa forma, vários artigos do Código Penal que se referem a crimes contra o trabalho. Eles são muito pouco utilizados. Se se procurar na jurisprudência, e mesmo nos livros de doutrina, referências a essas situações, encontram-se muito pouco na literatura jurídica. Isso significa que não há, de fato, um interesse maior das próprias autoridades judiciárias com relação ao tema, porque ele sempre aparece ocasionalmente.

Entendo que o artigo 149 do Código Penal, que faz menção à redução a situação análoga à da escravidão é um mecanismo insuficiente porque é vago. Analisando-o, pode-se entrar em toda uma discussão teórica, acadêmica, e não se chegar à conclusão alguma. É uma situação muito parecida com os crimes contra a organização do trabalho. Os instrumentos legais deveriam ser diuturnamente utilizados, mas pelas decisões da Justiça acabam ficando restringidos a um âmbito muito pequeno. Independentemente disso, o que estou querendo dizer é que todos queremos o aprimoramento gradativo não só das normas penais, mas também das normas do trabalho. O Direito deve ser dinâmico e de preferência refletir os interesses da sociedade naquele momento. Acredito que especificamente para essas práticas de trabalho escravo deveríamos ter instrumentos e mecanismos que poderiam, evidentemente, ser conciliados com a aplicação das penalidades devidas.

Foi exatamente pensando nisso que, em parceria com a Confederação Nacional dos Trabalhadores na Agricultura, realizamos uma pesquisa. Por ela, levantamos alguns dados para tentar elaborar um mapeamento do recrutamento de trabalhadores e desses caminhos que são percorridos para 
que pudéssemos identificar principalmente os focos de recrutamento que normalmente culminam em situações de escravidão. Concluído esse levantamento, ele deva ser aprimorado e permanentemente atualizado.

Ao serem identificados os focos de recrutamento de trabalhadores, deve-se buscar, mediante políticas públicas, conciliar a geração de emprego e renda. Parte dessa ação, eventualmente, deve ser assistencial, investimento no município para gerar algum tipo de possibilidade de desenvolvimento e oportunidade de trabalho. No meu modo de entender, essa alternativa impactaria de forma muito positiva e talvez mais rapidamente a vida dessas pessoas do que um processo tramitando na Justiça por cinco ou dez anos. Acima de tudo, considerando a vida e o bem-estar dessas pessoas, eu optaria por investir muito rápida e pesadamente nas políticas públicas voltadas para essas localidades, onde o recrutamento dos trabalhadores acontece há muitos anos.

Se examinarmos a situação dos trabalhadores em geral, principalmente em determinadas regiões do país, verificaremos que existem situações bem próximas do regime de escravidão. Do ponto de vista da precarização das condições de trabalho, encontraremos várias outras situações não tipicamente do trabalho escravo, que também irão, de alguma forma, incomodar nossos corações e mentes. Não sei se será possível revertê-la, porque essa situação que estamos vivendo é inerente ao próprio sistema capitalista. Sem dúvida alguma, deveremos juntar esforços para evitar também outra situação, que hoje denominamos de precarização da relação de trabalho. Evitar que ela chegue, também como um todo, à situação que hoje chamamos de escravidão. O limite entre uma e outra, em determinadas situações que ocorrem no Brasil, é muito tênue.

Minha expectativa é que, para o futuro, quando se voltar a falar de estatísticas do trabalho escravo, não se chegue mais à condição penosa de admitir que não conseguimos estabelecer grande diferenciação entre a situação do trabalho escravo e a dos trabalhadores de maneira geral, pois $50 \%$ da força de trabalho atuam hoje na informalidade, sem qualquer tipo de tutela.

\section{A atuação do GERTRAF}

ESTUDOS AVANÇADOS - Doutora Ruth, a senhora mencionou, em sua fala anterior, que o GERTRAF deveria ser reformulado. Não sei se a senhora se sente em condições de emitir opinião a esse respeito, levando-se em conta a sua situação funcional. 
$R$ uth Vilela - Não separo a minha situação de cidadã e meu exercício de cidadania da minha função. Sou funcionária pública, trabalho para o Estado, eventualmente trabalho para o governo quando estou ocupando um cargo de confiança. A minha visão é eminentemente técnica, não levo a minha militância política para o meu ambiente de trabalho, muito embora a minha ideologia faça com que eu trabalhe em determinada direção. A opinião que eu possa dar em relação a essas questões são fruto de uma experiência anterior. Enquanto funcionária do Estado, funcionária pública, todo o conhecimento que adquiri em razão do exercício dessa função enquanto servidora pública, todo esse conhecimento não é meu, particular, ele continua pertencendo ao Estado. Eu tive acesso a essas informações no exercício das minhas funções.

Ao afirmar que o GERTRAF não funcionou, falo isso com absoluta tranqüilidade, porque estou fazendo uma autocrítica. Pelo decreto e pela determinação, o grupo era presidido por mim. Estou fazendo uma confissão de que não tive competência suficiente para fazer esse grupo funcionar e para garantir aquela eficácia que o próprio presidente da República esperava ao elaborar o decreto. As justificativas não são desculpas. Elas são uma mera constatação das dificuldades que tivemos. Da primeira, já falei anteriormente, os ministérios indicaram pessoal de áreas técnicas, aliás, todos muito bons e muito interessados. Cada representante teria de voltar para seu próprio Ministério para dar o encaminhamento devido. Ora, esses representantes encontraram certa dificuldade devido ao nível hierárquico das pessoas que participam do GERTRAF, por não conseguirem garantir uma interlocução com quem tinha o poder de decisão. Isso é uma crítica que se faz, não é uma desculpa, mas uma constatação.

Por ser o Brasil um Estado historicamente corporativista e cartorial, temos o hábito de tratar nossas questões em compartimentos estanques. $\mathrm{O}$ professor Barelli sabe muito bem falar disso, porque no exercício de 93, no Ministério do Trabalho ele tentou bravamente superar essa coisa "da separação em caixinhas" Só que pretendíamos, por esse trabalho e essa discussão interinstitucional, construir e executar as políticas públicas necessárias para a erradicação do trabalho escravo. Mas cada ministério sempre prioriza o que está no seu próprio plano de trabalho. O que se tentávamos era que as diversas políticas fossem canalizadas para o combate ao trabalho escravo, mas infelizmente, não se conseguia. Tentamos de todas as formas. Todavia, o grupo não trabalhou inutilmente, porque conseguimos pelo menos obter pontos de contato e pontos de apoio nos diversos ministérios para buscar informações ou tomar a providência imediata que fosse necessária. Mas o grupo deixou de cumprir o grande papel a ele reservado, que era introduzir 
nos diversos ramos, nas diversas áreas, instrumentos, políticas, recursos, mecanismos que fossem canalizados para ser otimizados em relação ao combate ao trabalho escravo. A idéia, entretanto, acho que continua sendo magnifica. A importância desse grupo, acima de tudo, é que ele estava subordinado à Câmara de Políticas Sociais. A Câmara de Políticas Sociais, até onde sei, não está funcionando. Estava sendo objeto também de reavaliação. Acredito que nessa reavaliação da existência ou não de uma Câmara de Políticas Sociais, esse grupo automaticamente deve ser também reavaliado. Se não for possível a sua manutenção no mesmo formato, que se imagine um formato que garanta um pouco mais de eficácia do que já tivemos. Portanto, esse meu discurso é inclusive uma autocrítica, porque apesar de ter lutado muito, esse resultado realmente não posso apresentar.

ESTUDOS AVANÇADOS - Professor Barelli, deseja acrescentar algo mais?

Walter Barelli - A dificuldade que ela encontrou foi realmente essa. A Ruth era secretária da área de fiscalização do Ministério, e a sua contraparte em outro ministério não necessariamente teria o mesmo nível que ela tinha. Ela se reportava diretamente ao ministro. Possivelmente o outro assim não procedia. É uma questão muito difícil: como organizar e as pessoas terem ação de governo. Se era uma ação importante para o governo, para o presidente da República, as pessoas deveriam ter status equivalente, e isso é uma questão a se discutir no nível da administração pública. Se discutirmos aqui práticas da administração pública, sairíamos do tema. O que ocorreu, foi o que ela mencionou.

Continuo achando que só extinguiremos o trabalho escravo trabalhando com os representantes das diversas categorias. A idéia que já referi, o meu sonho, seria descer com avião ou helicóptero em uma fazenda com trabalho escravo, contando com a presença do presidente da Confederação Nacional da Agricultura, que se declarou contra o trabalho escravo quando ele era membro do Conselho Nacional do Trabalho. Continuo acreditando que é esse o caminho.

\section{Trabalho escravo nas cidades}

O que houve de mudança no mundo do trabalho nesses 30 e poucos anos? Houve evolução. Hoje, os empresários industriais vêem de outra maneira os sindicatos, as negociações coletivas, dependendo, é lógico, de cada região do país, mais avançados nos estados industrializados do que nos demais, mas isso se conseguiu levar para dentro do trabalho industrial. A mesma coisa tem de ser levada para o trabalho na agricultura. Quer dizer, é 
importante envolver aqueles que são os representantes eleitos da área rural e expulsar da categoria de empresário aquele que for escravizador. Ele tem de ser excluído da sociedade, e a melhor forma é ser excluído da sua categoria representativa.

Agora, tudo muda, estamos observando que inicialmente as denúncias eram policiais. Aparecia um trabalhador todo machucado, perdido na floresta, e a imprensa fazia a denúncia. Daí, começou, e devemos reconhecer, o papel da Igreja, e das igrejas, não só a CPT. Outras igrejas entraram na denúncia porque elas estavam presentes. Em determinadas localidades possivelmente não existe prefeitura, não tem governo do estado, não tem governo federal, mas certamente há um templo nas proximidades. Á medida em que começou a haver essa organização, ela foi importante.

Os sindicatos, pelas características brasileiras, não conseguiram denunciar porque eles não têm condições de entrar nas propriedades. Os fiscais do Ministério do Trabalho têm todas as prerrogativas, mas para entrar em determinados locais, só com a polícia federal armada, porque ali é terra de selvageria, não quero usar o termo farwest. Representa bem a idéia da anomia, como já mencionei, ou da lei do proprietário: ele é o dono, ele propõe, a própria autoridade federal, para entrar, para estar presente, tem de ser manu militare. Os sindicatos começam a ter maior participação, mas ainda estão muito na atividade da denúncia. Se as centrais considerassem território seu o território de fronteiras agrícolas, talvez assim começassem a ter uma atuação mais positiva.

Concordo com tudo o que a Ruth mencionou. Ela é uma autoridade no campo. A precarização está acontecendo em todas as formas de trabalho, e também ocorre na zona urbana. Mencionei o problema das empregadas domésticas nas cidades menos organizadas. Aqui, em São Paulo, certamente também se encontra o problema. Outra ocorrência que se começa a constatar em São Paulo é o trabalho escravo do imigrante, do boliviano. Isso já ocorreu com os coreanos, hoje eles têm outro status. A situação se dá pela retenção do passaporte do imigrante, a quem se diz: "você não está legalizado, se sair vai ser preso". É preciso passar por subterrâneos para localizá-los. Temos vários casos... o caso dos bolivianos, na indústria da confecção, em São Paulo, por exemplo. Não podemos, nesse dossiê que o IEA está fazendo, perder essa visão. Não estamos nos referindo apenas à fronteira agrícola, ao trabalhador desconhecido, mas também àqueles dos países vizinhos, de onde pessoas vêm para a nossa principal cidade para refazer o mesmo tipo de história, história dos primórdios da Primeira Revolução Industrial. Sei que também o Ministério tem trabalhado nessa direção. 
O sindicato das costureiras tem denunciado, parece que houve um ato em que denunciavam esses fatos. Mas a grande dificuldade é organizar, porque temos de ir exatamente aos subterrâneos. São casas escondidas, da mesma forma como ocorre na floresta, que quando chega a fiscalização as pessoas desaparecem. Também nessas casas, quando a fiscalização aparece, nada há para ser investigado, porque já se deu um jeito de esconder o crime contra o trabalho.

ESTUDOS AVANÇADOS - Mais alguma coisa, doutora Ruth?

$R$ uth Vilela - Às vezes nos entusiasmamos, nos emocionamos com o relato e nos esquecemos de grandes detalhes. Uma coisa interessante de se deixar registrada é o seguinte: assim como a Comissão Pastoral da Terra e outras organizações não afrouxam nunca o cerco com relação ao trabalho escravo, precisaríamos começar a nos organizar de forma mais ampla. Como o ministro Barelli mencionou, são várias as situações atentatórias à dignidade humana, aos direitos humanos e aos direitos trabalhistas. Nesse aspecto, acredito que o IEA pode realizar um trabalho bastante relevante. Não estou querendo pautar, absolutamente, a revista de vocês. Mas, seria muito interessante a divulgação de uma matéria sobre essa precarização dos direitos dos trabalhadores. Ela tem relação com tudo: tem relação direta com os rumos da economia, tem relação com as possibilidades de desenvolvimento, com a agricultura, com a indústria. É um tema, digamos, que impacta todas as outras coisas da nossa vida.

Além disso, só para finalizar, queria ressaltar que a questão do aprimoramento da legislação é fator de extrema importância, mas que não pode definitivamente ser encarado de forma isolada. Essas ações têm de ser complementares, cada um desempenhando o seu papel. Nós, do Ministério do Trabalho, temos desempenhado nossas funções de forma cada vez mais aprimorada. O governo, em momento algum, desistiu de aprimorar esse trabalho. O nosso presidente, inclusive, é um especialista em trabalho escravo, até com livros publicados sobre o tema. Durante todo o tempo em que estive à frente da Secretaria, à frente desse trabalho, quero registrar que tive o apoio direto não só do ministro Paulo Paiva, mas também o apoio direto da própria presidência da República. Acredito ser relevante registrar como é importante perceber que todas as pessoas estão abertas e dispostas a executar políticas públicas em conjunto. Temos o apoio principal do presidente da República, o apoio da própria Casa Civil e o trabalho continua sendo executado pelo Ministério do Trabalho. Vários parlamentares sempre estão diretamente envolvidos nessa questão, se interessam, dão apoio. Conseguimos mudar um pouca a mentalidade imperante. Contamos até com o apoio de alguns parlamentares que inicialmente faziam pressão contrária. Acredi- 
to que, acima de tudo, o diálogo tem de estar aberto, até com quem age e pensa de forma diferente. Como o Barelli mencionou, devemos buscar permanentemente o diálogo com a representação patronal, que é principalmente a Confederação Nacional da Agricultura, e ao mesmo tempo com a representação dos trabalhadores.

Ninguém consegue fazer absolutamente nada isoladamente. Nem o Ministério do Trabalho conseguirá bons resultados se estiver apenas agindo com o Grupo Móvel, nem a polícia federal agindo isoladamente conseguiria os resultados que hoje estamos obtendo para preservar os direitos trabalhistas. Não conseguiremos avançar sem o apoio das demais instituições, de outros ministérios e dos governos locais.

Walter Barelli - Gostaria de fazer uma nota de rodapé. Quando se mencionou pressão, houve pressão, sim, e ela é constante em cima dos fiscais. Quando estávamos trabalhando no Bico de Papagaio o nosso delegado regional do trabalho e os fiscais que estavam na operação foram todos ameaçados de morte, tanto assim que na operação posterior levamos fiscais de outras regiões, porque não eram conhecidos. O fiscal que fica em uma cidade importante, como Marabá, exerce sua função, mas tem de ser um herói, porque ele sabe que, ali, a lei é outra coisa. Não é texto escrito, é a força, muitas vezes, uma arma, uma metralhadora. 